\title{
Assessment of interactions of efavirenz solid drug nanoparticles with human immunological and haematological systems
}

Neill J. Liptrott ${ }^{1,3^{*}}$, Marco Giardiello², Tom O. McDonald², Steve P. Rannard ${ }^{2,3}$ and Andrew Owen ${ }^{1,3}$

\begin{abstract}
Background: Recent work has developed solid drug nanoparticles (SDNs) of efavirenz that have been demonstrated, preclinically, improved oral bioavailability and the potential to enable up to a 50\% dose reduction, and is currently being studied in a healthy volunteer clinical trial. Other SDN formulations are being studied for parenteral administration, either as intramuscular long-acting formulations, or for direct administration intravenously. The interaction of nanoparticles with the immunological and haematological systems can be a major barrier to successful translation but has been understudied for SDN formulations. Here we have conducted a preclinical evaluation of efavirenz SDN to assess their potential interaction with these systems. Platelet aggregation and activation, plasma coagulation, haemolysis, complement activation, T cell functionality and phenotype, monocyte derived macrophage functionality, and NK cell function were assessed in primary healthy volunteer samples treated with either aqueous efavirenz or efavirenz SDN.
\end{abstract}

Results: Efavirenz SDNs were shown not to interfere with any of the systems studied in terms of immunostimulation nor immunosuppression. Although efavirenz aqueous solution was shown to cause significant haemolysis ex vivo, efavirenz SDNs did not. No other interaction with haematological systems was observed. Efavirenz SDNs have been demonstrated to be immunologically and haematologically inert in the utilised assays.

Conclusions: Taken collectively, along with the recent observation that lopinavir SDN formulations did not impact immunological responses, these data indicate that this type of nanoformulation does not elicit immunological consequences seen with other types of nanomaterial. The methodologies presented here provide a framework for pre-emptive preclinical characterisation of nanoparticle safety.

Keywords: HIV, Antiretroviral, Biocompatibility, Immunotoxicity, Haematotoxicity

\section{Background}

Nanomedicine offers the potential for therapeutic benefits across indications, sometimes without the cost of discovering new active pharmaceutical ingredients (APIs). However, the behaviour of certain nanomaterials has been demonstrated to differ considerably from larger bulk material [1]. The production and use of engineered nanomaterials is constantly expanding, but there remain

\footnotetext{
*Correspondence: Neill.liptrott@liverpool.ac.uk

${ }^{1}$ Department of Molecular and Clinical Pharmacology, Institute of Translational Medicine, The University of Liverpool, 70 Pembroke Place, Block H, First Floor, Liverpool L69 3GF, UK

Full list of author information is available at the end of the article
}

uncertainties surrounding the potential risks posed to human health and the environment.

The size of nanomaterials influences their toxicity [1] and has been consistently demonstrated for nanomaterials encountered in workplace environments (e.g. carbon black, polystyrene, titanium dioxide and silver) [2-5]. The physicochemical characteristics of nanomaterials such as charge, surface area, solubility, surface chemistry and shape show a large degree of heterogeneity amongst materials both developed and in development. Immune stimulation, immune suppression and immune modulation have all been reported for nanomaterials $[6,7]$ partly as a result of the formation of a protein corona made up 
of serum proteins [8-13]. Opsonisation of nanomaterials by serum proteins such as immunoglobulins and complement proteins results in rapid uptake into cells such as macrophages and dendritic cells [10, 14]. Interactions with serum proteins may render nanomaterials antigenic and it has been suggested that functionalisation (e.g. with growth factors, receptors) may induce neutralising antibodies that also recognise the body's own molecules with implications similar to those for biotechnology-derived therapeutics $[15,16]$. Indeed, anti-nanoparticle antibody formation in response to $\mathrm{C}_{60}$ fullerene nanomaterials has been reported [17, 18]. Some studies suggest that nanoparticles can also exacerbate allergic reactions [19]. Immune cells recognise nanoparticles based on their surface properties and core composition and mount inflammatory responses but many of the molecular events are poorly understood [20].

In general, positively charged nanomaterials are more likely to induce inflammatory reactions than negatively charged or neutral materials. For example, positively charged 4.5 amine terminated polyaminoamine (PAMAM) dendrimers do not cause human leukocytes to secrete cytokines [7] but some charged liposomes induce secretion of cytokines such as IL-2 and IFNY [21]. Several studies have addressed the influence of nanoparticles on Th1 and Th2 responses. Large $(>1 \mu \mathrm{m})$ particles have been shown to induce Th1 responses, whereas smaller ones $(<500 \mathrm{~nm})$ are associated with Th2 response [22]. In contrast, some engineered nanoparticles such as $500 \mathrm{~nm}$ poly(lactic-co-glycolic) acid (PLGA) [23, 24], $270 \mathrm{~nm}$ PLGA [25], $80 \mathrm{~nm}$ and $100 \mathrm{~nm}$ nanoemulsions $[26,27]$ and $123 \mathrm{~nm}$ dendrosomes [28] induce a Th1 response. Other engineered particles (e.g. $5 \mathrm{~nm}$ generation-5 PAMAM dendrimers) do not cause inflammatory reactions in vivo, but weakly induce Th2 cytokine production and enhance immunoglobulin production [29]. There are also reports of nanomaterials suppressing immune responses-generation 3.5 PAMAM dendrimers conjugated to glucosamine strongly inhibit induction of inflammatory cytokines in macrophages and dendritic cells exposed to endotoxin [30], and amino-terminated generation-5 PAMAM dendrimers suppress inflammatory cytokine secretion in vitro and in vivo [31]. Conversely, unopsonised silica nanoparticles have been shown to stimulate macrophages to produce inflammatory proteins [32]. Natural killer (NK) cells are an integral part of the innate immune system but also serve to bridge the adaptive immune system [33, 34]. As natural killer cells play a vital role in anti-tumour [35] and antiviral immunity [36], perturbation of their function may exacerbate existing conditions. Previous work has shown that multi-walled carbon nanotubes suppress NK function in vivo [37].
In addition to interactions with immunological systems there are numerous reports of nanomaterials interacting with components of the blood coagulation system. This has been eloquently reviewed in a recent review paper from the National Cancer Institute's Nanotechnology Characterisation Laboratory [38]. Oral and intravenous administration of generation-4 and generation-7 PAMAM dendrimers resulted in disseminated intravascular coagulopathy (DIC) in mice [39]. With respect to platelet aggregation, cationic polystyrene latex nanoparticles induced platelet activation and aggregation through cellular membrane perturbation whilst their anionic counterparts activated platelets and induced their aggregation through the classical pathway involving the upregulation of adhesion receptors [40]. Activation of complement has also been demonstrated for perfluorocarbon (PFC)-based emulsions [41]. In addition to activation of these pathways, damage to erythrocytes has been reported for silver nanomaterials where nano-sized particles were found to be significantly more haemolytic than micron-sized particles [42].

Currently, commercial nanomedicines are synthesised as nanocarriers or solid drug nanoparticles (SDNs). Nanocarriers are predominantly parenteral options, targeting therapies to specific cells or tissues, but for chronic diseases daily parenteral administration has consistently failed to meet patient needs, and drug delivery vehicles add risk. SDNs overcome some these problems, providing oral administration formats and more recently, opportunities for long-acting parenteral administration. Our new emulsion-templated freeze-drying technique widens the range of drugs that can be formulated into SDNs to include hydrolytically sensitive APIs [43]. The overwhelming majority of the studies conducted to date have focused upon nanomaterials with a lipid-, polymeror inorganic composition. There is a current paucity of knowledge regarding whether solid drug nanoparticles (SDNs) elicit such responses, leading to issues with biocompatibility, despite this nanotechnology being the most clinically and commercially successful approach to date. We recently reported that lopinavir SDNs were relatively inert in ex vivo analyses of immunological responses, but there is a need to understand whether this applies across SDNs made from different therapeutic agents [44]. Therefore, we investigated a series of immune-activation/ suppression criteria to assess whether the efavirenz SDNs trigger or interfere with immune responses, and to determine their blood contact properties. In order to determine the impact of nanoformulation on immunological effects, all incubations were conducted with matched drug concentrations of efavirenz between aqueous and nanoformulated drug. 


\section{Methods}

Preparation, and analysis, of emulsion-templated freeze-dried monoliths containing efavirenz nanoparticles Samples are prepared using a $70 \mathrm{mg} / \mathrm{mL}$ stock solution of Efavirenz (EFV) in chloroform, a $22.5 \mathrm{mg} / \mathrm{mL}$ of poly(vinyl alcohol) $(\mathrm{MW}=9500 \mathrm{~g} / \mathrm{mol}, \mathrm{PVA})$ in water and a $22.5 \mathrm{mg} / \mathrm{mL}$ stock solution of $\alpha$-tocopherol polyethylene glycol succinate (TPGS) in water. Stock solutions are added in the following proportion; $100 \mu \mathrm{L} \mathrm{EFV;}$ $90 \mu \mathrm{L}$ PVA, $45 \mu \mathrm{L}$ TPGS and $265 \mu \mathrm{L}$ of water, therefore solid mass is $10 \mathrm{mg}$ with the ratio; 70\% EFV, 20\% PVA and $10 \%$ TPGS in a $1: 4$ oil to water $(\mathrm{O} / \mathrm{W})$ mix. Where needed, radiolabeled EFV SDNs were prepared by incorporation of ${ }^{14} \mathrm{C}$-labeled $\mathrm{EFV}\left(0.1 \mu \mathrm{Ci}{ }^{14} \mathrm{C}\right)$ into the chloroform internal phase of the emulsion during the stock solution preparation. The mixtures are the emulsified using a Covaris S2x for $30 \mathrm{~s}$ with a duty cycle of 20 , an intensity of 10 and 500 cycles/burst in frequency sweeping mode. After which, the samples were immediately cryogenically frozen and lyophilized using a Virtis benchtop $\mathrm{K}$ freeze-drier for $48 \mathrm{~h}$ to produce off white dry porous monolith products. Samples were then sealed in individual vials until analysis. In order to determine the dispersed SDN particle characteristics, samples were dispersed by addition of $3.5 \mathrm{~mL}$ of water (therefore $1 \mathrm{mg} / \mathrm{mL}$ with respect to EFV content). Z-average diameter $\left(D_{z}\right)$, Zeta potential $(\zeta)$ and polydispersity index (PdI) were determined by dynamic light scattering at a temperature of $25{ }^{\circ} \mathrm{C}$ using a Malvern Zetasizer Nano ZS equipped with a $4 \mathrm{~mW} \mathrm{He}-\mathrm{Ne}, 633 \mathrm{~nm}$ laser and using plastic disposable cuvettes. Malvern Zetasizer software version 6.20 was used for data analysis. Zeta potential measurements were also carried out at $1 \mathrm{mg} / \mathrm{mL}, 25^{\circ} \mathrm{C}$, and an initial $\mathrm{pH}$ of 6.5 , using disposable capillary zeta cells. Size, zeta potential and polydispersity measurements were obtained as an average of three individual measurements and were obtained using the instrument's automatic optimisation settings.

Assessment of endotoxin concentration in sample material by limulus amoebocyte lysate (LAL) analysis (turbidimetric) Standard lipopolysaccharide (LPS) from E. coli was reconstituted to a final concentration of $1000 \mathrm{EU} / \mathrm{mL}$ in pyrogen-free LAL water. Further dilutions were then made in pyrogen-free LAL water to produce a standard curve of $1,0.1,0.01$ and $0.001 \mathrm{EU} / \mathrm{mL}$. LAL was reconstituted in Glucashield buffer to prevent possible interference by $\beta$-glucans that may be present in sample materials. Negative control consisted of pyrogen-free LAL water only and positive control $0.05 \mathrm{EU} / \mathrm{mL}$ LPS. Samples of aqueous efavirenz and SDNs were prepared in pyrogen-free LAL water at concentrations of 4 and $40 \mu \mathrm{g}$ / $\mathrm{mL}$. Inhibition/enhancement (IEC) controls consisted of test samples containing 0.05 EU/mL LPS. Reactions consisted of standard, sample or control with the addition of LAL $(50 \mu \mathrm{L})$. Samples were then analysed using a Pyros Kinetic Flex reader (American Associates of Cape Cod). Results from each individual assay run were not considered valid unless the precision and accuracy of the standard curve $\left(r^{2} \geq 0.980\right)$ and quality control were within $25 \%$, and the inhibition/enhancement control exhibited 50-200\% spike recovery.

Assessment of endotoxin concentration in sample material by limulus amoebocyte lysate ( $L A L)$ analysis (gel-clot)

Samples were prepared as for turbidimetric analysis with the exception of standard curve samples which were prepared as $0.25 \lambda$ to $2 \lambda$ ( $\lambda$ is the sensitivity provided for each lot of the lysate by the manufacturer). IEC were prepared in $0.25 \lambda$ to $2 \lambda$ samples to assess interference with assay. Samples were incubated for $1 \mathrm{~h}$ at $37^{\circ} \mathrm{C}$ in an unstirred water bath. Following incubation sample tubes were inverted to assess the formation of a clot.

\section{Determination of possible microbial contamination in sample materials}

To determine if microbial contamination was present in sample materials $50 \mu \mathrm{L}(1 \mathrm{mg} / \mathrm{mL})$ of material was streaked onto LB agar plates and incubated in a humidified incubator at $37{ }^{\circ} \mathrm{C}$ for $48 \mathrm{~h}$. E. coli stock solution (10 CFU/mL) was used as a positive control for microbial growth. Following incubation, plates were visually inspected for signs of microbial growth and recorded digitally.

\section{Determination of possible mycoplasma contamination in sample materials}

H460 cells were treated with sample materials $(4 \mu \mathrm{g} / \mathrm{mL})$ and passaged every $48 \mathrm{~h}$ in RPMI-1640 media containing $10 \%$ FBS. At each passage a sample of culture supernatant fraction was retained for mycoplasma analysis. After 18 passages, the first and last passage samples were analysed for the presence of mycoplasma using endpoint PCR containing specific probe sequences as part of a commercially available mycoplasma detection kit (Venor GeM Mycoplasma detection Kit [45]).

\section{Impact of efavirenz solid drug nanoparticles on platelet aggregation}

Platelet rich plasma (PRP) was prepared from healthy volunteer whole blood in sodium citrate by centrifugation at $250 \times g$ for $8 \mathrm{~min}$. Platelet poor plasma (PPP) was prepared by centrifugation of whole blood at $2500 \times g$ for $10 \mathrm{~min}$. PRP was treated with either 4 or $40 \mu \mathrm{g} / \mathrm{mL}$ of sample materials (EFV dissolved in DMSO, 0.5\% DMSO used for subsequent assays) for $15 \mathrm{~min}$ at $37{ }^{\circ} \mathrm{C}$. PPP was 
used as a background control and also treated with the same concentrations of sample materials. Samples were analysed using a Chrono-log aggregometer, gain was set to 0.005 and optical baseline established using PPP controls. Platelet aggregation (turbidity) and ATP release (luminescence) were recorded as area under the curve for treated and untreated samples. Collagen $(1 \mu \mathrm{g} / \mathrm{mL})$ was used as a positive control for platelet aggregation and materials were also tested in the presence of collagen to ensure inhibition of aggregation did not occur.

\section{Assessment of plasma coagulation in the presence of nanoparticles}

Human blood from three donors was collected by venepuncture into tubes anti-coagulated with sodium citrate; blood was used within $1 \mathrm{~h}$ of collection. Test plasma was prepared by centrifuging blood at $2500 \times g$, at $21{ }^{\circ} \mathrm{C}$, for $10 \mathrm{~min}$ with the resultant plasma collected and pooled. Pooled plasma was stable at room temperature for $8 \mathrm{~h}$. Samples (either conventional EFV or EFV $\mathrm{SDN}$ ) were prepared at $10 \times$ the required final concentration to accommodate dilution when added to test plasma. Final concentrations tested were 40, 4, 0.8 and $0.16 \mu \mathrm{g} /$ $\mathrm{mL}$. Samples were mixed with test plasma and incubated at $37^{\circ} \mathrm{C}$ for $30 \mathrm{~min}$. Each preparation was prepared in triplicate. Lyophilised controls representing normal and abnormal plasma (plasma with coagulation delay) were reconstituted with distilled water $(2 \mathrm{~mL})$ and left to equilibrate to room temperature $30 \mathrm{~min}$ prior to use. These controls are used as instrumentation controls for the STArt4 coagulometer (Diagnositca Stago). Instrument test parameters (as outlined in Additional file 1: Table S1) were set up for each assay target. Assays are designed to capture interactions of nanoemulsions with components of the three major coagulation pathways; intrinsic pathway (also known as the contact activation pathway, because it is activated by a damaged surface), extrinsic pathway (also known as the tissue factor pathway) and the final common pathway. Activated partial thromboplastin time (APTT) assay is used to assess the intrinsic pathway while the prothrombin time (PT) assay is a measure of the extrinsic pathway. Thrombin time (TT) is an indicator of the functionality of the final common pathway. Cuvettes were placed into A, B, C and D test rows on the coagulometer and one metal ball added into each cuvette (warmed for at least 3 min prior to use). $100 \mu \mathrm{L}$ of either control or test plasma was added to a cuvette when testing PT or thrombin time and $50 \mu \mathrm{L}$ when testing APTT with three duplicate cuvettes for each plasma sample. Additionally, for the APTT assays $50 \mu \mathrm{L}$ of PTT-A was also added. Timer was started for each of the test rows and cuvettes transferred to PIP row $10 \mathrm{~s}$ prior to alarm notification. Once incubation time was complete, coagulation reagent (see Additional file 1: Table S1) was added to each cuvette and coagulation time recorded. Percentage coefficient of variation was calculated for each control and test samples according to the following formula:

$$
\% \mathrm{CV}=\mathrm{SD} / \text { Mean } \times 100 \% \text {. }
$$

If $\% \mathrm{CV}$ was greater than $5 \%$ for study samples that sample was reanalysed. Data was expressed as a percentage of the coagulation time recorded for plasma with no SDNs present (plasma only control).

\section{Determination of possible haemolysis attributed to solid drug nanoparticles}

Haemolysis was determined using cyanomethaemoglobin $(\mathrm{CMH})$ reagent and a haemoglobin standard. A standard curve of known haemoglobin concentrations was created (range $0.025-0.8 \mathrm{mg} / \mathrm{mL})$ with low $(0.0625 \mathrm{mg} / \mathrm{mL})$, medium $(0.125 \mathrm{mg} / \mathrm{mL})$ and high $(0.625 \mathrm{mg} / \mathrm{mL})$ quality control samples. Triton X100 was included as a positive control. Sample materials were tested at a range of concentrations $(0.16,0.8,4$ and $40 \mu \mathrm{g} / \mathrm{mL})$. Whole blood was collected from healthy volunteers in Li-heparin tubes and pooled blood prepared by mixing equal volumes of blood from each donor. An aliquot of pooled whole blood was taken and centrifuged at $800 \times g$ for $15 \mathrm{~min}$ to determine plasma free haemoglobin (PFH). Briefly, $200 \mu \mathrm{L}$ of calibration standard, quality controls and blanks were added to respective wells of a 96 well plate. Total blood haemoglobin (TBH) $(200 \mu \mathrm{L}$, prepared by combining $20 \mu \mathrm{L}$ of pooled whole blood and $5 \mathrm{~mL}$ of cyanomethaemoglobin) was added to each well. $100 \mu \mathrm{L}$ of plasma (for PFH) was added per well. Finally, $100 \mu \mathrm{L}$ of $\mathrm{CMH}$ reagent was added to each well containing samples. Plates were covered with a plate sealer and gently shaken for 1-2 min. Absorbance at $540 \mathrm{~nm}$ was read to determine haemoglobin concentration. Remaining pooled whole blood was diluted with $\mathrm{Ca}^{2+} / \mathrm{Mg}^{2+}$ Dulbecco's phosphate buffered saline (DPBS) to adjust total blood haemoglobin concentration to $10 \pm 2 \mathrm{mg} / \mathrm{mL}$ (TBHd). In a separate universal tube $100 \mu \mathrm{L}$ of test sample, blank or positive/negative control was added. $\mathrm{Ca}^{2+} / \mathrm{Mg}^{2+}$ DPBS $(700 \mu \mathrm{L})$ was then added to each tube and $100 \mu \mathrm{L}$ of TBHd to each test sample. In parallel $100 \mu \mathrm{L}$ of $\mathrm{Ca}^{2+} / \mathrm{Mg}^{2+}$ DPBS was added to separate tubes to represent a "no blood" control to evaluate potential interference of the sample materials with the assay. Tubes were covered and mixed gently avoiding vortexing which may damage erythrocytes. Tubes were then placed in an incubator at $37^{\circ} \mathrm{C}$ for $3 \mathrm{~h}( \pm 15 \mathrm{~min})$ and samples were mixed every $30 \mathrm{~min}$. Following incubation tubes were centrifuged at $800 \times g$ for $15 \mathrm{~min}$. A fresh set of calibrators and controls were prepared as previously. To a fresh 96 well plate $200 \mu \mathrm{L}$ of blank reagent, 
calibrators, and quality controls of TBHd was added to each well. $100 \mu \mathrm{L}$ of test samples, positive and negative controls were also added to the plate followed by $100 \mu \mathrm{L}$ of $\mathrm{CMH}$ reagent to every well. The plate was covered with a plate sealer and shaken gently on a plate shaker for 1-2 min. Absorbance at $540 \mathrm{~nm}$ was measured spectrophotometrically and the \% $\mathrm{CV}$ and percent difference from theoretical percentage difference from theoretical (PDFT) were calculated. Assays were accepted if \%CV and PDFT were within $20 \%$.

\section{Assessment of possible complement activation by efavirenz solid drug nanoparticles}

Blood was collected from healthy volunteers in tubes containing sodium citrate as anticoagulant. Plasma was prepared by centrifugation of blood samples at $2500 \times g$ for $10 \mathrm{~min}$. Plasma was evaluated visually for haemolysis; plasma deemed to be haemolysed was not used to prepare the plasma pool. Plasma was used for complement testing within $1 \mathrm{~h}$ of collection. Pooled plasma was combined with either test material (at concentrations of 0.16 , $0.8,4$ and $40 \mu \mathrm{g} / \mathrm{mL}$ ) or positive control (cobra venom factor) or negative control ( $0.9 \%$ saline). Plasma was also treated with a generic form of Paclitaxel as a clinically relevant comparison for possible complement activation. Samples were incubated for $30 \mathrm{~min}$ at $37^{\circ} \mathrm{C}$. Following incubation, the manufacturers guidelines were then followed for completion of the iC3b ELISA. Optical density of the samples was measured at $405 \mathrm{~nm}$.

\section{Isolation of peripheral blood mononuclear cells from peripheral blood samples}

Healthy volunteer blood was collected from the National Blood Service (Liverpool, UK) or from healthy volunteers within the department. For the latter, healthy volunteer blood was collected via venepuncture under ethics approval from the University Physical Interventions sub-committee (Reference RETH000563). Informed consent was given and accepted by the healthy volunteers for use of whole blood in subsequent assays. All samples were anonymised. Blood was layered over ficoll in a 2:1 ratio and centrifuged at $2000 \mathrm{rpm}$ for $30 \mathrm{~min}\left(4{ }^{\circ} \mathrm{C}\right)$. The peripheral blood mononuclear cell (PBMC) interface was then removed and transferred to a fresh universal tube prior to being washed three times in PBS. PBMC were then counted and resuspended to the required density for subsequent experiments.

\section{Activation of PBMC using CD2, CD3 and CD28 conjugated MACSiBead particles}

Prior to use, MACSiBead particles were prepared according to the manufacturers guidelines. MACSiBead particles $\left(2.5 \times 10^{6}\right)$ were transferred to a sterile universal tube with $200 \mu \mathrm{L}$ of fresh culture media RPMI-1640, 10\% FCS) was added and centrifuged (1500 rpm) for $5 \mathrm{~min}$. The supernatant fraction was aspirated and MACSiBeads were resuspended in $100 \mu \mathrm{L}$ of fresh culture media. PBMC were resuspended in culture media $(900 \mu \mathrm{L})$ at a density of $5 \times 10^{6}$ cells. PBMC and MACSiBeads were combined and incubated at $37^{\circ} \mathrm{C}$ for $24 \mathrm{~h}$. Culture conditions consisted of unactivated PBMC, MACSiBead-activated PBMC, MACSiBead-activated PBMC cocultured with efavirenz or the SDN counterpart $(10 \mu \mathrm{M})$, PBMC cultured with efavirenz or its SDN counterpart, $(10 \mu \mathrm{M})$ and PBMC incubated for $24 \mathrm{~h}$ with efavirenz or its SDN counterpart for $24 \mathrm{~h}$ prior to activation with MACSiBead particles.

\section{Preparation and activation of primary monocyte derived macrophage (MDM) from healthy volunteers}

PBMC were isolated from healthy volunteer whole blood via density gradient centrifugation using Ficoll-Paque. CD14+ positive cells were isolated from PBMC via magnetic bead based cell separation. CD14+ cells were then cultured for 10 days in Iscove's Modified Dulbecco's medium (IMDM) containing human serum (20\%) and Macrophage colony stimulating factor (M-CSF, $10 \mathrm{ng} /$ $\mathrm{mL}$ ). Following differentiation into MDM, cells were incubated in the presence of lipopolysaccharide (LPS, $1 \mu \mathrm{g} / \mathrm{mL})$, conventional efavirenz $(10 \mu \mathrm{M})$ or efavirenz SDNs $(10 \mu \mathrm{M})$ for $24 \mathrm{~h}$. Cell culture supernatant fractions were then harvested for cytokine analysis.

\section{Measurement of cytokine concentrations in activated PBMC and MDM cultures}

Aliquots of culture supernatant fractions $(100 \mu \mathrm{L})$ were taken for analysis of cytokine secretion. Determination of cytokine concentrations was carried out using multiplex cytokine assays conducted using the Bioplex 200 system (Biorad). IL-2, IL-10 and IFN $\gamma$ were measured for PBMC stimulation and IL-1 $\beta$, IL-6, IL- 8 and TNF $\alpha$ were measured for MDM stimulation. Briefly, coupled beads $(50 \mu \mathrm{L})$ were added to every well on a 96 well plate. Plates were washed with wash buffer three times using a vacuum manifold prior to cell culture supernatant fractions $(50 \mu \mathrm{L})$ being added to the plate alongside multiplexed standard curves for relevant cytokines. Samples were incubated on a plate shaker at room temperature for $30 \mathrm{~min}$. Plates were then washed three times prior to the addition of detection antibodies $(25 \mu \mathrm{L})$ and then incubated on a plate shaker at room temperature for $30 \mathrm{~min}$. Plates were again washed three times prior to the addition of streptavadin-PE antibodies $(50 \mu \mathrm{L})$ and incubation on a plate shaker for $10 \mathrm{~min}$. Plates were then washed for a final three times and assay buffer $(125 \mu \mathrm{L})$ added to 
wells. Plates were then analysed on a Bioplex 200 analyser using recommended gating settings.

\section{Analysis of activation markers in CD4 and CD8 T cells}

Prior to analysis of activation marker expression by flow cytometry MACSiBeads were removed from cell cultures by resuspending $\mathrm{PBMC}$ in buffer (PBS, pH7.2; $0.5 \%$ human serum albumin; $2 \mathrm{mM}$ EDTA) to a density of $5 \times 10^{6} / \mathrm{mL}$ and placing the tube in a magnetic field (MACSiMAG separator) for $5 \mathrm{~min}$. The supernatant fraction containing the cells was carefully removed and placed in a fresh tube. The tube was removed from magnetic field, buffer added and the process repeated to maximise recovery of cells. PBMC samples were then stained with either CD4-FITC or CD8-FITC conjugated antibodies $(1: 11)$ in buffer for $30 \mathrm{~min}$ to enable gating of CD4+ and CD8+ $\mathrm{T}$ cells along with a combination of antibodies against either CD25-PE, CD44-APC, CD69-APC or CD95-APC. Samples were then washed three times in buffer before analysis on a BD FACSCantoII flow cytometer. The PBMC population was gated using linear forward and side scatter.

\section{Analysis of cell proliferation in PBMC treated with PHA by incorporation of ${ }^{3} \mathrm{H}$-thymidine}

Cell density of PBMC was adjusted to $2.5 \times 10^{6}$ cells per $\mathrm{mL}$ and plated at $100 \mu \mathrm{L}$ per well $(25,000$ cells per well) in a 96 well round bottomed plate. $50 \mu \mathrm{L}$ of phytohaemagglutinin (PHA) $(20 \mu \mathrm{g} / \mathrm{mL})$ was then added per well. $50 \mu \mathrm{L}$ of either medium or medium containing drug (efavirenz or efavirenz SDNs, $10 \mu \mathrm{M}$ ) was added to the wells in triplicate. Plates were then cultured for $48 \mathrm{~h}\left(37^{\circ} \mathrm{C} ; 5 \%\right.$ $\mathrm{CO}_{2}$ ), the final $16 \mathrm{~h}$ with $1 \mu \mathrm{Ci}\left[{ }^{3} \mathrm{H}\right]$-thymidine per well. Cell were then harvested onto a filtermat using a tomtec harvester 96 and sealed in a sample bag with melt on scint. Incorporated radioactivity was counted on a Perkin-Elmer MicroBeta detector.

\section{Analysis of phagocytosis in primary monocyte derived macrophages}

CD14+ cells were isolated from PBMC samples by magnetic bead separation and incubated in IMDM media containing M-CSF $(10 \mathrm{ng} / \mathrm{mL})$ for 12 days replacing the media every 3 days to differentiate into monocyte derived macrophages (MDM). Following differentiation, MDM were treated with efavirenz or the efavirenz SDNs $(10 \mu \mathrm{M})$ for $24 \mathrm{~h}$. Following incubation, determination of phagocytic capacity was achieved using pHrodo reagent (Molecular probes, UK). Briefly, MDM were harvested and plated out in a black 96 well plate at 100,000 cells per well. pHrodo ${ }^{\mathrm{TM}}$ BioParticles ${ }^{\circledR}$ were prepared by resuspending $2 \mathrm{mg}$ of lyophilized product in $2 \mathrm{~mL}$ of uptake buffer (Hanks Balanced Salt Solution, 20 mM HEPES, $\mathrm{pH}$ 7.4) and briefly vortexed to completely resuspend the particles. Cytochalasin B $(10 \mu \mathrm{M})$ was used as a positive control for inhibition of phagocytosis. Culture media was removed from each well and replaced with the pHrodo bioparticle solution $(100 \mu \mathrm{L})$. The plate was covered and transferred to an incubator at $37{ }^{\circ} \mathrm{C}$ without $\mathrm{CO}_{2}$ to prevent artificial acidification of the uptake buffer thereby minimising background signal. Plates were read using a plate reader with an excitation of $550 \mathrm{nM}$ and emission of $600 \mathrm{nM}$.

\section{Accumulation of radiolabelled efavirenz solid drug nanoparticles in monocyte derived macrophages}

Monocyte derived macrophages were generated as described above and treated with Dynasore $(100 \mu \mathrm{M})$, indomethacin $(100 \mu \mathrm{M})$ or cytochalasin $\mathrm{B}(5 \mu \mathrm{M})$ for $24 \mathrm{~h}$ prior to the addition of radiolabelled efavirenz SDNs $(0.3 \mu \mathrm{Ci}, 10 \mu \mathrm{M})$ for $1 \mathrm{~h}$. Following incubation cells were centrifuged (9000 rpm, $1 \mathrm{~min}$ ) and an aliquot of supernatant fraction $(100 \mu \mathrm{L}$, extracellular sample) taken and placed in a scintillation vial.

\section{Measurement of efavirenz solid drug nanoparticle effects on cytotoxic activity of NK cells by label-free RT-CES system} Effector cells (NK92) were prepared at $1 \times 10^{6}$ cells/ $\mathrm{mL}$ and treated with test nanoparticles for $24 \mathrm{~h}$. Target cell (HepG2) density was adjusted to $0.5 \times 10^{6}$ cells/ mL. Media (50 $\mu \mathrm{L}$ RPMI-1640) was added to all wells and plate attached to RT-CES, starting the appropriate program. Following background measurement, HepG2 $(50 \mu \mathrm{L})$ were added per well of the RT-CES plate and data acquisition started. HepG2 cells were left in culture for approximately $16-20 \mathrm{~h}$ prior to the addition of NK92 cells. On the 2nd day, NK92 cell viability was determined and cells readjusted to a density of $25 . \times 10^{6}$ viable cells/ $\mathrm{mL}$ resulting in an effector to target (E:T) ratio of 5:1. RTCES program was paused for the addition of NK92 cells then returned to incubator to resume data acquisition for a further $24 \mathrm{~h}$. On day 3, data acquisition was stopped and the data analysed by assessing the area under the curve (AUC) for each sample.

\section{Statistical analysis}

Distribution of the data was assessed using a ShapiroWilk test. For comparisons between datasets either an unpaired t test or a Mann-Whitney test was used for normally and non-normally distributed data respectively. Stats Direct software (version 3.0.171) was used for data analysis and a $\mathrm{P}$ value $<0.05$ was considered statistically significant. 


\section{Results}

Characterisation of efavirenz solid drug nanoparticles

A $1 \mathrm{mg} / \mathrm{mL}$ (with respect to EFV content) dispersion of efavirenz SDN was made in deionised water, phosphate buffered saline (PBS) or $\mathrm{NaCl}(10 \mathrm{mM})$. Hydrodynamic diameter (Z-average) and zeta potential were assessed in each of these dispersions to determine their impact on physical-chemical characteristics (PCC). There was no significant difference in size for SDNs dispersed in deionised water $(264 \pm 5 \mathrm{~nm})$ compared to SDN dispersed in PBS $(300 \pm 16 \mathrm{~nm})$ or $\mathrm{NaCl}(289 \pm 12 \mathrm{~nm}$; Additional file 2: Figure S1a). Additional file 2: Figure S1b shows polydispersity indices (PDI) for SDNs dispersed in deionised water, PBS and $\mathrm{NaCl}$. Efavirenz SDNs dispersed in PBS $(0.402 \pm 0.055 ; \mathrm{P}<0.001)$ and $\mathrm{NaCl}(0.377 \pm 0.064$; $\mathrm{P}<0.001)$ had a significantly greater PDI than those in deionised water $(0.278 \pm 0.035)$. Efavirenz SDN zeta potential were also assessed at native $\mathrm{pH}$ of the dispersion $(\mathrm{pH} 7.89)$ and titrated to neutral $\mathrm{pH}$ (7.09). The zeta potential was nearly neutral in both cases.

\section{Assessment of possible endotoxin or microbial contamination}

Using a turbidimetric LAL assay the concentration of endotoxin was assessed in dispersed SDNs as well as an aqueous solution of EFV. The mean concentration of endotoxin in the aqueous solution of EFV and the EFV SDN dispersion was found to $<0.001$ and $0.0306 \mathrm{EU} / \mathrm{mL}$ respectively. This was confirmed by gel-clot LAL assay. In order to ensure there was no inhibition of the LAL assay by a known concentration of endotoxin (0.05 EU/ $\mathrm{mL}$ ) was spiked into sample materials prior to turbidimetric LAL analysis with an acceptable range of recovery between 50 and $200 \%$. Recovery of endotoxin within aqueous EFV and EFV SDN was 179 and $180 \%$ respectively and therefore within acceptable parameters.

Additionally, $\mathrm{H} 460$ cells were treated with $1 \mathrm{mg} / \mathrm{mL}$ of either efavirenz solution or efavirenz SDN and passaged every $48 \mathrm{~h}$ for 18 passages. Samples were taken at every passage and then samples were analysed by PCR for mycoplasma contamination. No mycoplasma was detected after treatment with sample materials.

Sample materials were spread on LB agar plates at a concentration of 4 and $40 \mu \mathrm{g} / \mathrm{mL}$ and incubated for $48 \mathrm{~h}$; images of the culture plates are shown in Additional file 3: Figure S2. A culture of E. coli was also plated out as a positive control and Additional file 3: Figure S2a shows growth after $48 \mathrm{~h}$ whilst a negative control of LAL reagent water shows no growth (Additional file 3: Figure S2b) after the same period of time. No growth was observed for either aqueous EFV or EFV SDN at either 4 or $40 \mu \mathrm{g} / \mathrm{mL}$ after $48 \mathrm{~h}$.

\section{Impact of efavirenz solid drug nanoparticles on platelet aggregation}

Efavirenz SDNs were tested for their impact on platelet aggregation and activation at 4 and $40 \mu \mathrm{g} / \mathrm{mL}$. Saline $(0.9 \%)$ was used as a negative control for platelet activation and collagen $(1 \mu \mathrm{g} / \mathrm{mL})$ used as a positive control. Platelet aggregation was defined as the area under the curve (AUC) for the turbidimetric assessment and activation by the slope of the curve produced for ATP release. Collagen resulted in a 300 -fold greater AUC than that generated by saline solution. Neither the efavirenz solution, nor SDNs, caused aggregation of platelets at either 4 or $40 \mu \mathrm{g} / \mathrm{mL}$ (Fig. 1a). Platelet aggregation was induced by collagen and samples treated with aqueous efavirenz solution or efavirenz SDN. No significant impact on collagen induced platelet aggregation was observed (Fig. 1b). These observations were further confirmed by ATP release from platelets. Tested materials did not cause significant ATP release from platelets nor did they inhibit ATP release from platelets activated by collagen (Fig. 1c, $\mathrm{d}$, respectively).

\section{Impact of efavirenz solid drug nanoparticles on plasma coagulation pathways}

The impact of efavirenz solution and efavirenz SDNs on the three main pathways of plasma coagulation (intrinsic, extrinsic and common pathways) was assessed by measuring activated partial thromboplastin time (APTT), prothrombin time (PT) and thrombin time (TT), respectively. A prolongation of plasma coagulation time is associated with interference with coagulation cascades. Plasma coagulation times for the three pathways studied following treatment is summarised in Fig. 2. No marked difference in plasma coagulation time for samples treated with either efavirenz aqueous solution or efavirenz SDNs.

\section{Assessment of potential haemolysis caused by efavirenz solid drug nanoparticles}

Haemolysis was assessed by determining the amount of free haemoglobin in samples treated with either aqueous efavirenz or efavirenz SDNs. Efavirenz aqueous solution and SDNs were tested at concentrations of $0.16,0.8$, 4 and $40 \mu \mathrm{g} / \mathrm{mL}$ efavirenz. Materials were also tested in the absence of blood to ensure no interference with the assay. A percentage haemolysis between 5 and $25 \%$ has previously been accepted as not of any direct concern [46-49]. Figure 3 summarises the percentage haemolysis caused by treatment of blood with efavirenz solution or efavirenz SDNs. Treatment of blood with $0.9 \%$ saline solution resulted in $3.3 \%$ haemolysis. Haemolysis caused by $0.16,0.8,4$ and $40 \mu \mathrm{g} / \mathrm{mL}$ efavirenz solution was 4.29 , $2.61,0.04$ and $86.2 \%$, respectively. Percentage haemolysis 

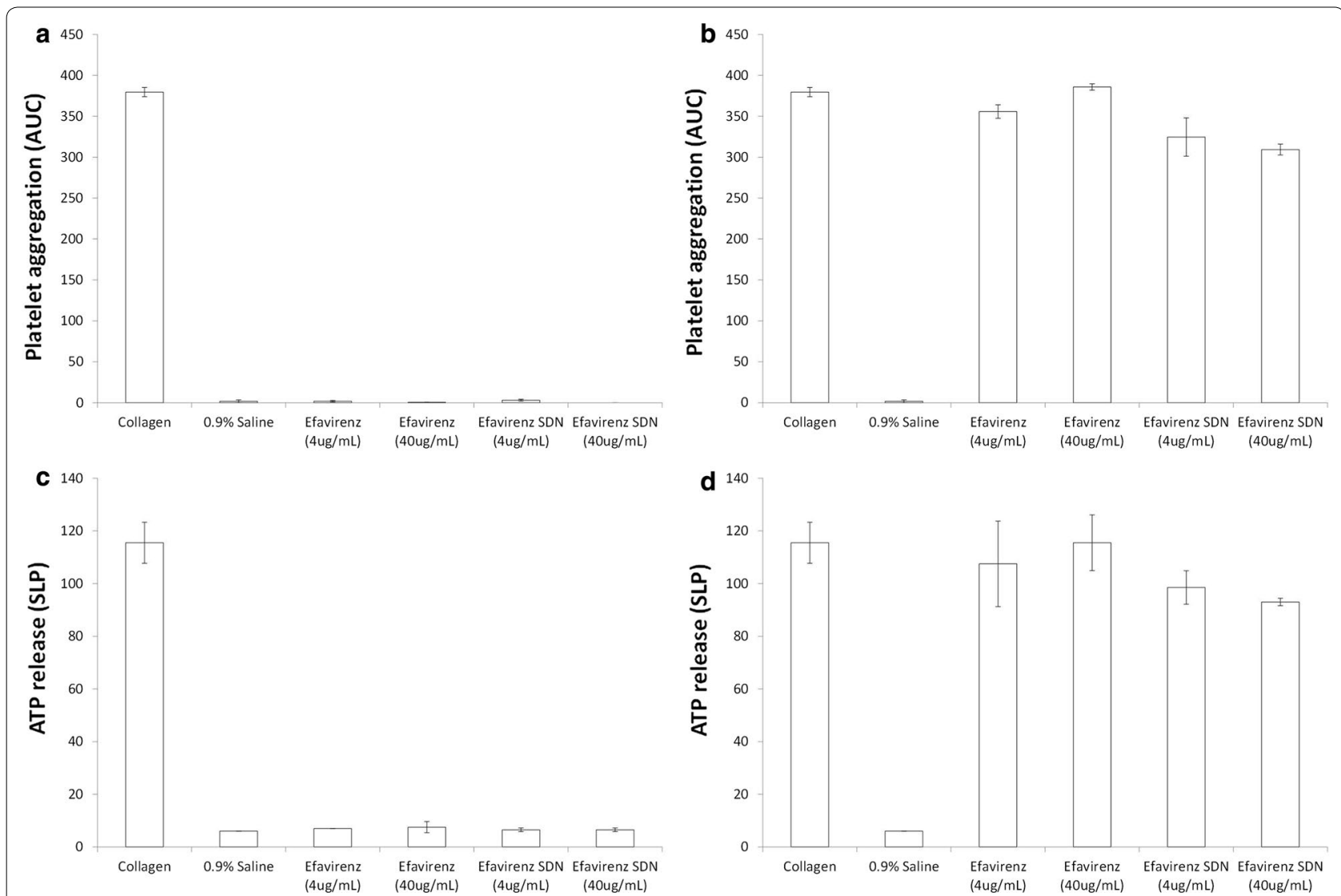

Fig. 1 Response of primary human platelets to efavirenz and efavirenz solid drug nanoparticles. Platelet aggregation was assessed in response to materials alone (a) and that induced by collagen (b). Platelet activation was assessed by ATP release in non-induced (c) and collagen induced (d) platelets. Data expressed as mean \pm standard deviation

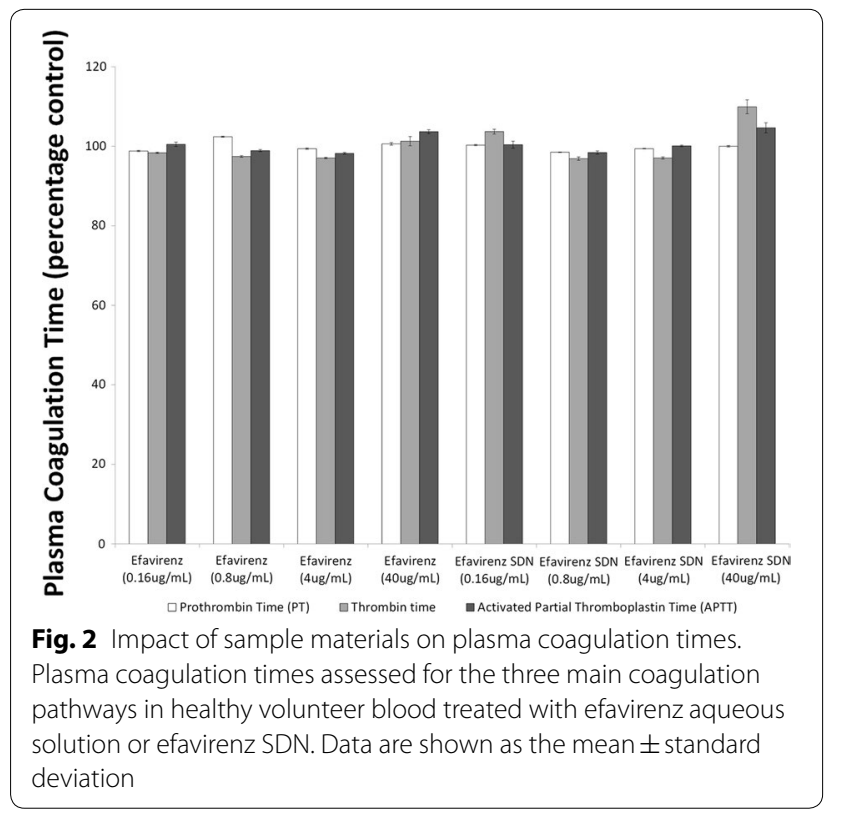

caused by efavirenz SDNs at $0.16,0.8,4$ and $40 \mu \mathrm{g} / \mathrm{mL}$ was $1.6,2.08,1.63$ and $0.17 \%$, respectively.

\section{Determination of possible complement activation}

The concentration of iC3b in plasma treated with efavirenz aqueous solution or efavirenz SDNs (summarised in Fig. 4) was determined as a possible measure of complement activation by either the classical or alternative pathway. Cobra venom factor (positive control) yielded a very strong increase in the concentration of iC3b $(196.8 \mu \mathrm{g} / \mathrm{mL})$ whereas $0.9 \%$ saline (negative control) yielded only $6.3 \mu \mathrm{g} / \mathrm{mL}$ of iC3b, which was below the limit of quantification of the assay. Similarly for all tested materials, no activation of complement occurred, as evidenced by increased concentrations of $\mathrm{iC} 3 \mathrm{~b}$, since all values were below the limit of quantification. Paclitaxel was included as a clinically relevant positive control with known activation of complement [50] and was shown to result in an increase in iC3b concentrations $(30 \mu \mathrm{g} / \mathrm{mL})$. 


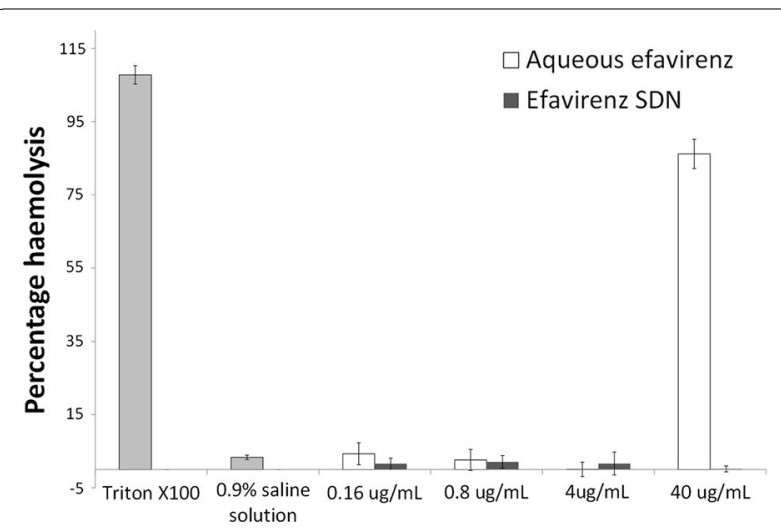

Fig. 3 Extent of haemolysis in healthy volunteer blood treated with efavirenz aqueous solution and efavirenz SDN. Healthy volunteer blood was treated with a range of concentrations of test materials for $3 \mathrm{~h}$ at $37^{\circ} \mathrm{C}$. Percent haemolysis was determined by assessing the amount of free haemoglobin present in samples post incubation

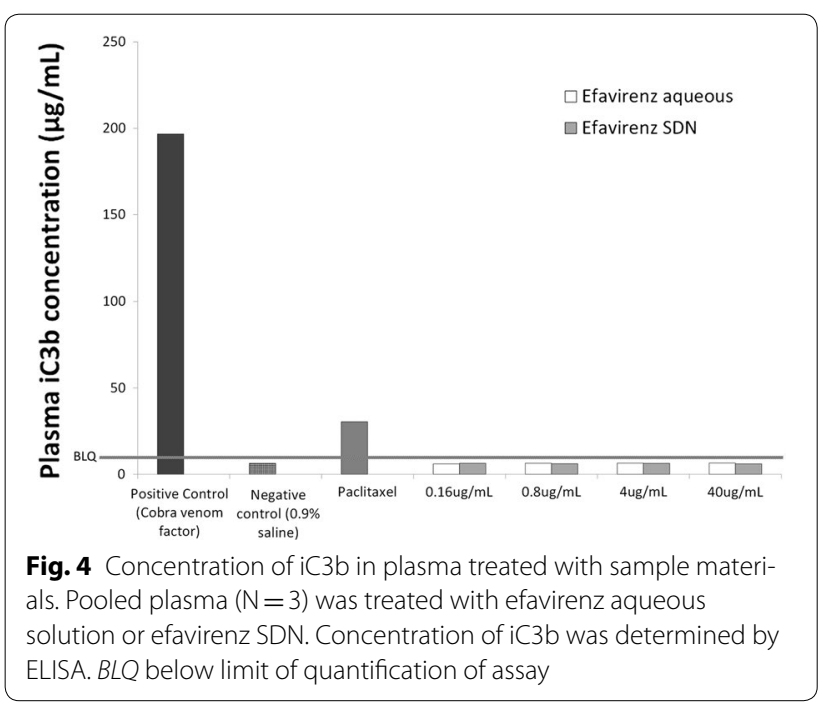

\section{Impact of efavirenz solid drug nanoparticles on T cell function and phenotype}

The proliferation of lymphocytes in response to PHA and/or sample materials was assessed using ${ }^{3} \mathrm{H}$-thymidine incorporation. There was no significant difference in ${ }^{3} \mathrm{H}$-thymidine incorporation between untreated, control cells and cells treated with either efavirenz solution or SDNs (Fig. 5a). Treatment with PHA caused proliferation and thereby significantly increased ${ }^{3} \mathrm{H}$-thymidine incorporation in PHA treated cells compared to untreated cells (51-fold increase, $\mathrm{P}=0.02$ ). A similar fold increase was observed for cells treated with PHA and efavirenz aqueous solution (57-fold increase, $\mathrm{P}=0.01$ ) and cells treated with PHA and efavirenz SDNs (61-fold increase, $\mathrm{P}=0.01$ ). No significant difference was observed in the proliferation of cells treated with PHA with efavirenz aqueous solution $(\mathrm{P}=0.16)$ and $\mathrm{PHA}$ with efavirenz SDNs $(\mathrm{P}=0.18)$.

Secretion of IL-2, IL-10 and IFNy was assessed in PBMC samples treated with sample materials (Fig. 5b) for $24 \mathrm{~h}$. Anti-CD2/CD3/CD28 beads were used as a positive control for stimulation of $\mathrm{T}$ cells and were shown to significantly increase the secretion of IL-2 (148-fold greater, $\mathrm{P}=0.0002$ ), IL-10 (58-fold greater, $\mathrm{P}=0.0006$ ) and IFN $\gamma$ (42-fold greater, $\mathrm{P}=0.0002)$. Secretion of IL-10 from cells treated with efavirenz aqueous solution or efavirenz SDNs was not significantly different from untreated cells. However, IL-2 secretion was significantly lower from cells treated with efavirenz aqueous solution (sixfold lower, $\mathrm{P}=0.015$ ) and efavirenz SDNs (threefold lower, $\mathrm{P}=0.0008)$. IFN $\gamma$ was similarly affected but concentrations were reduced to below the limit of detection rendering statistical comparison impossible. IL-2 secretion from cells stimulated with beads and treated with efavirenz aqueous solution (1.6-fold lower, $\mathrm{P}=0.038$ ) and efavirenz SDN (1.6-fold lower, $\mathrm{P}=0.09$ ) was significantly lower than that of cells stimulated solely with beads but there was no significant difference between the two treatments. A similar effect was observed for IL-10 (efavirenz aqueous solution, 1.4-fold lower, $\mathrm{P}=0.0035$; efavirenz SDNs, 1.2-fold lower, $\mathrm{P}=0.04$ ) and IFN $\gamma$ (efavirenz aqueous solution, twofold lower, $\mathrm{P}=0.039$; efavirenz SDNs, twofold lower, $\mathrm{P}=0.037$ ). However, there was again no significant difference was observed between solution and SDNs.

Surface markers of $\mathrm{T}$ cell activation were measured in CD4+ and CD8+ cells and data are summarised in Fig. 5c, d, respectively. On CD4+ cells, expression of CD25 (twofold greater, $\mathrm{P}=0.045), \mathrm{CD} 44$ (1.3-fold greater, $\mathrm{P}=0.015$ ), CD69 (fourfold greater, $\mathrm{P}=0.03$ ) and CD95 (1.2-fold greater, $\mathrm{P}=0.045)$ was higher than in unstimulated cells. Similar effects were seen in CD8 + cells with respect to CD25 (eightfold greater, $\mathrm{P}=0.045$ ), CD44 (1.25-fold greater, $\mathrm{P}=0.05)$, CD69 (2.2-fold greater, $\mathrm{P}=0.01)$ and CD95 (1.9-fold greater, $\mathrm{P}=0.04$ ) expression. Incubation of cells with either efavirenz aqueous solution or efavirenz SDNs did not significantly affect the expression of surface markers of activation.

\section{Impact of solid drug nanoparticles on monocyte derived macrophage function}

Monocyte derived macrophages (MDM) were treated with LPS, efavirenz aqueous solution or efavirenz SDNs for $24 \mathrm{~h}$ (Fig. 6a). Following incubation, aliquots of cell culture supernatant fraction were taken and analysed for concentrations of IL-1 $\beta$, IL-6, IL- 8 and TNF $\alpha$. LPS treatment resulted in greater secretion of IL-1 $\beta$ (31-fold greater, $\mathrm{P}=0.03$ ), IL-6 (1360-fold greater, $\mathrm{P}=0.03)$, IL-8 

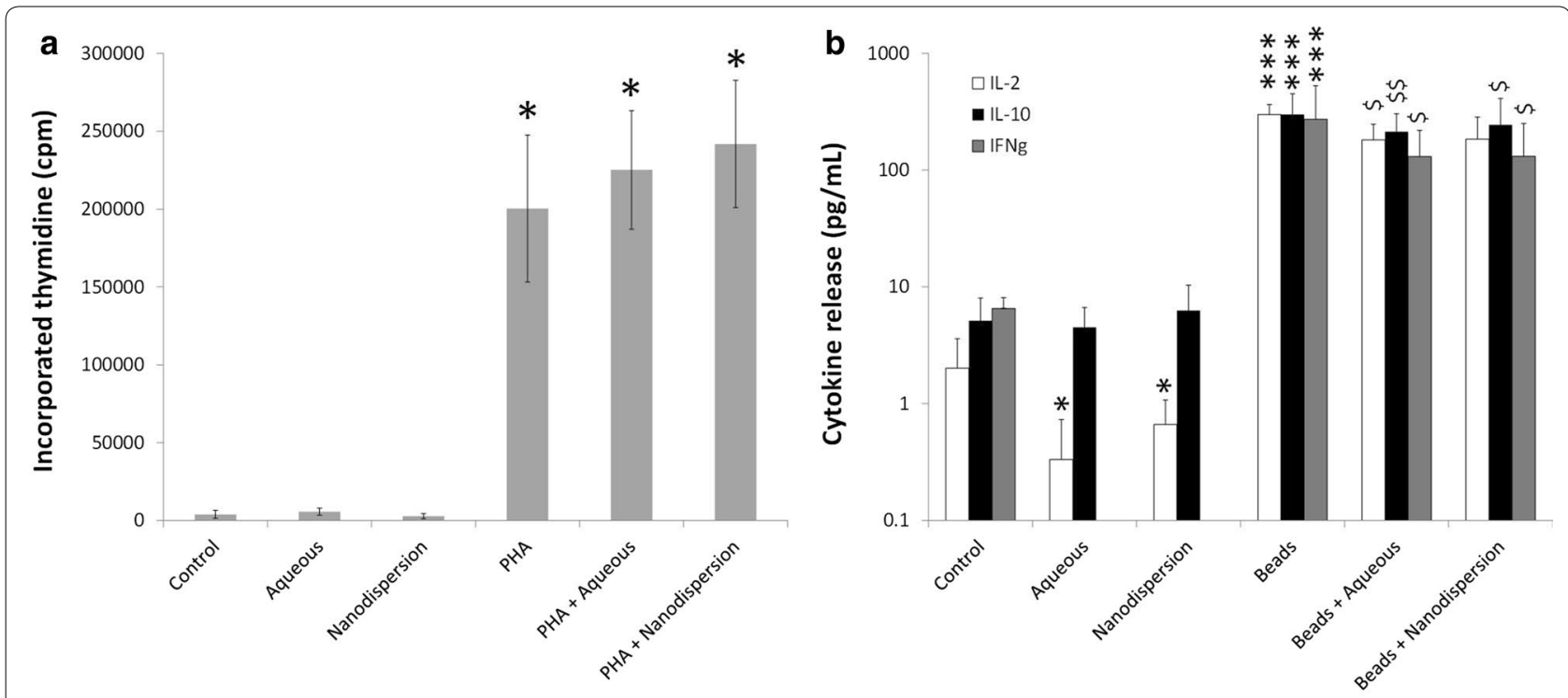

C
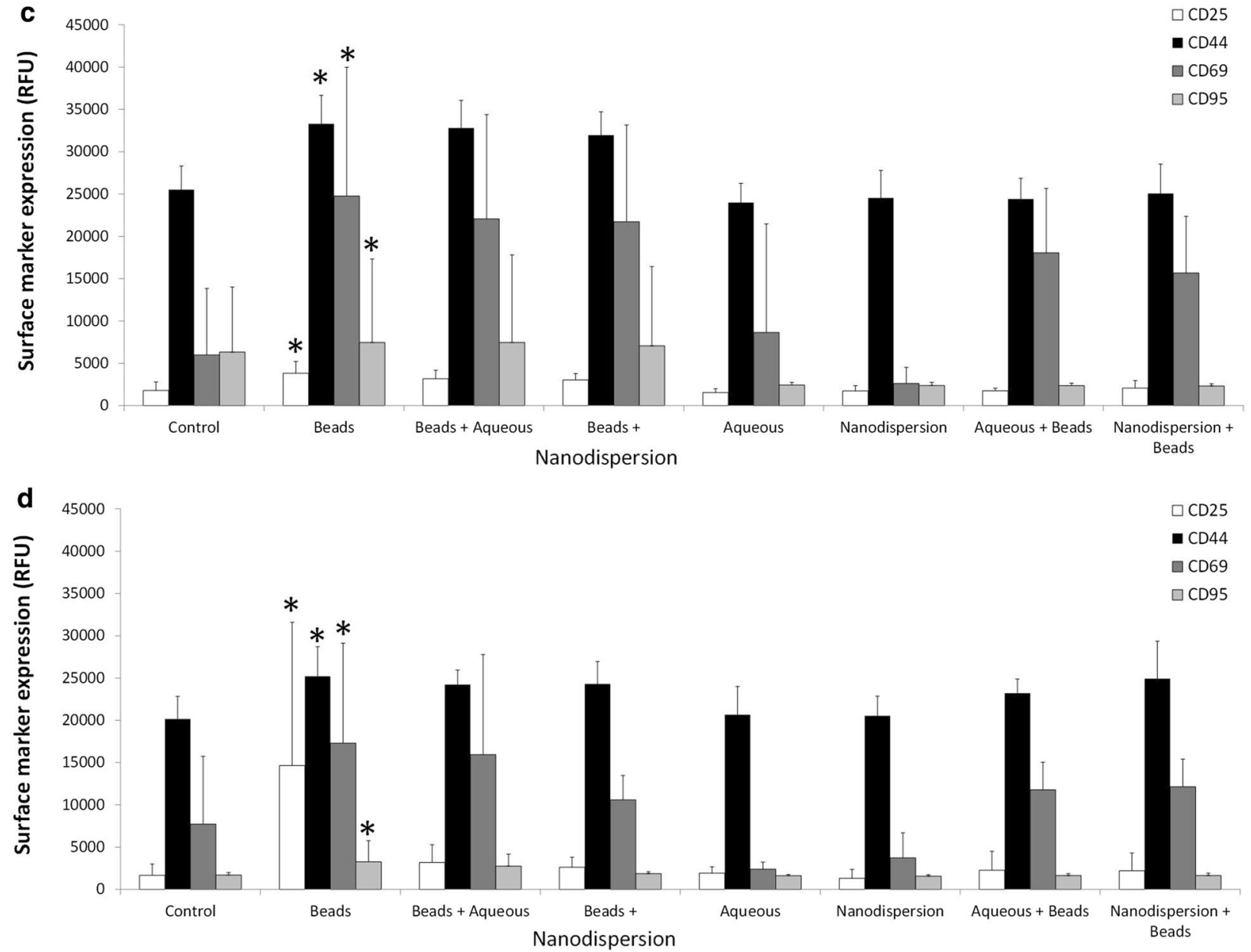

Fig. 5 Characterisation of the potential interaction between solid drug nanoparticles and lymphocyte function. PBMC were treated with either efavirenz aqueous solution or efavirenz s for $24 \mathrm{~h}$ before their proliferative capacity (a), cytokine secretion (b) and surface marker expression in $\mathrm{CD} 4+(\mathbf{c})$ and $\mathrm{CD} 8+(\mathbf{d})$ cells were determined. Data expressed as mean \pm standard deviation $(\mathrm{N}=5) ;{ }^{*} \mathrm{P}<0.05,{ }^{* *} \mathrm{P}<0.01$, ${ }^{* * *} \mathrm{P}<0.001$ as compared to untreated control whereas ${ }^{\$} P<0.05,{ }^{\$} P<0.01,{ }^{\$ \$} P<0.001$ compared to positive control 

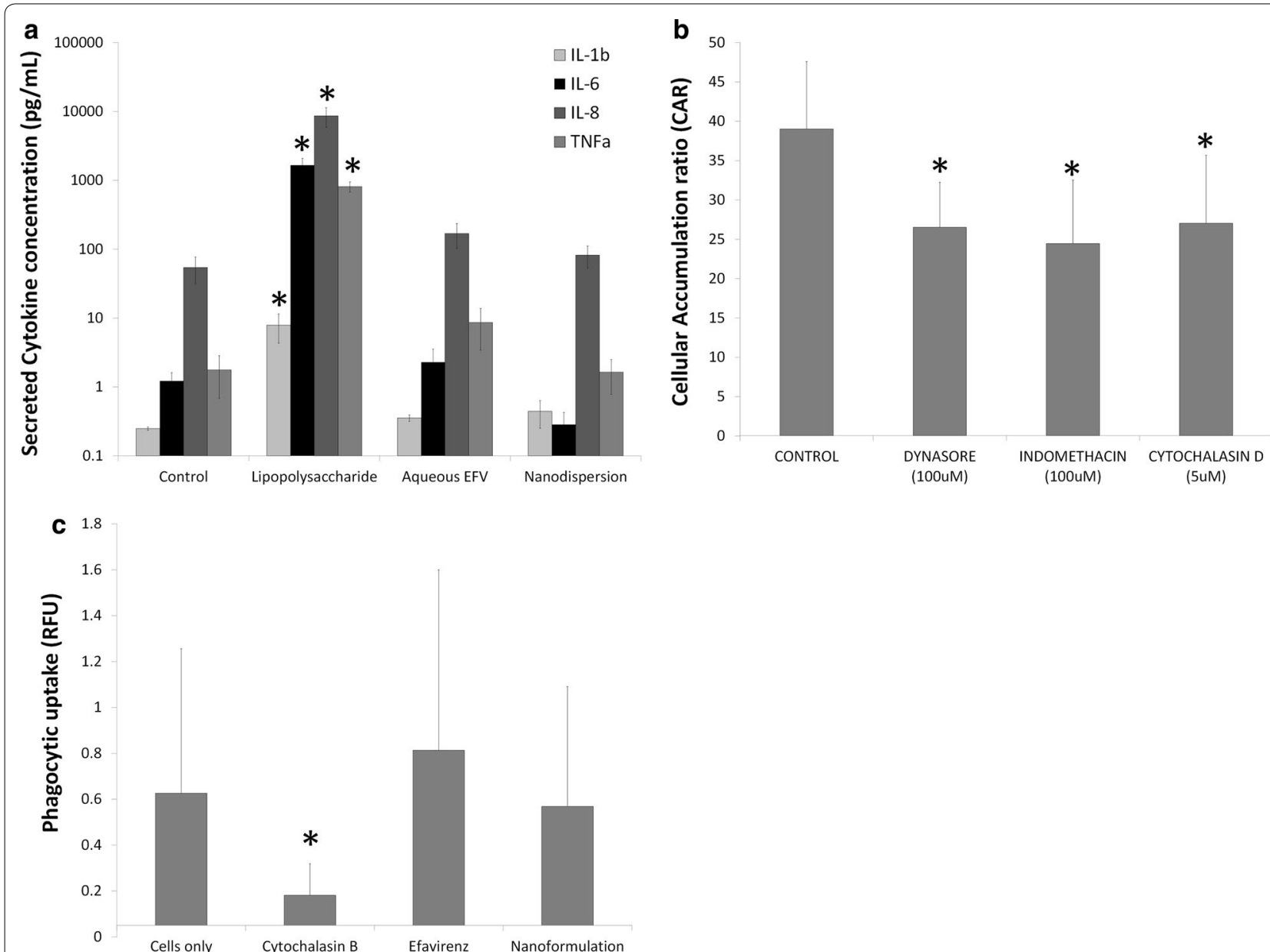

Fig. 6 Characterisation of the potential impact of efavirenz solid drug nanoparticles on monocyte derived macrophage function. MDM were treated with either efavirenz aqueous solution or efavirenz s for $24 \mathrm{~h}$ before their cytokine secretion (a) was assessed. LPS included as a positive control. Uptake of efavirenz s was also assessed $(\mathbf{b})$ in addition to the phagocytic capacity of MDM treated with sample materials. Data expressed as mean \pm standard deviation $(\mathrm{N}=5) ;{ }^{*} \mathrm{P}<0.05,{ }^{* *} \mathrm{P}<0.01,{ }^{* * *} \mathrm{P}<0.001$ as compared to untreated control

(158-fold greater, $\mathrm{P}=0.03)$ and TNF $\alpha$ (458-fold greater, $\mathrm{P}=0.03)$. Neither efavirenz aqueous solution nor efavirenz SDNs significantly affected cytokine secretion from MDM.

The accumulation of efavirenz SDNs in MDM was also assessed incorporating inhibitors of clathrin mediated endocytosis (Dynasore), caveolae mediated endocytosis (indomethacin) and phagocytosis (cytochalasin B) (Fig. 6b). All inhibitors reduced the accumulation of efavirenz SDNs (Dynasore, 1.47-fold lower accumulation, $\mathrm{P}=0.047$; Indomethacin, 1.59-fold lower accumulation, $\mathrm{P}=0.047$; cytochalasin $\mathrm{B}, 1.44$-fold reduction, $\mathrm{P}=0.048)$.

As phagocytosis appears to be involved in the uptake of efavirenz SDNs their impact on the phagocytosis of fluorescent $E$. coli bioparticles by MDM was also assessed to ensure no interference with function (Fig. 6c). Cytochalasin B was included as a positive control and showed a 3.4-fold lower $(P=0.04)$ accumulation of bioparticles in MDM. Uptake of fluorescent bioparticles by MDM was not significantly affected by either efavirenz aqueous solution or efavirenz SDNs (Fig. 6c).

Impact of efavirenz and efavirenz solid drug nanoparticles on NK cell cytotoxicity

NK cell cytotoxicity was assessed using NK92 cells as effector cells and HepG2 as target cells and measuring cell viability via electrical impedance generated by HepG2 attachment to RT-CES plates. Treatment of HepG2 cells with NK92 cells resulted in a 52\% lower viability compared to HepG2 cells grown in monoculture (Fig. 7). Treatment of NK92 cells with efavirenz aqueous solution for $24 \mathrm{~h}$ resulted in no significant change in their cytotoxic capability (Fig. 7a). Similarly, treatment of NK92 cells with efavirenz SDNs did not significantly affect their cytotoxic capability (Fig. 7b). 

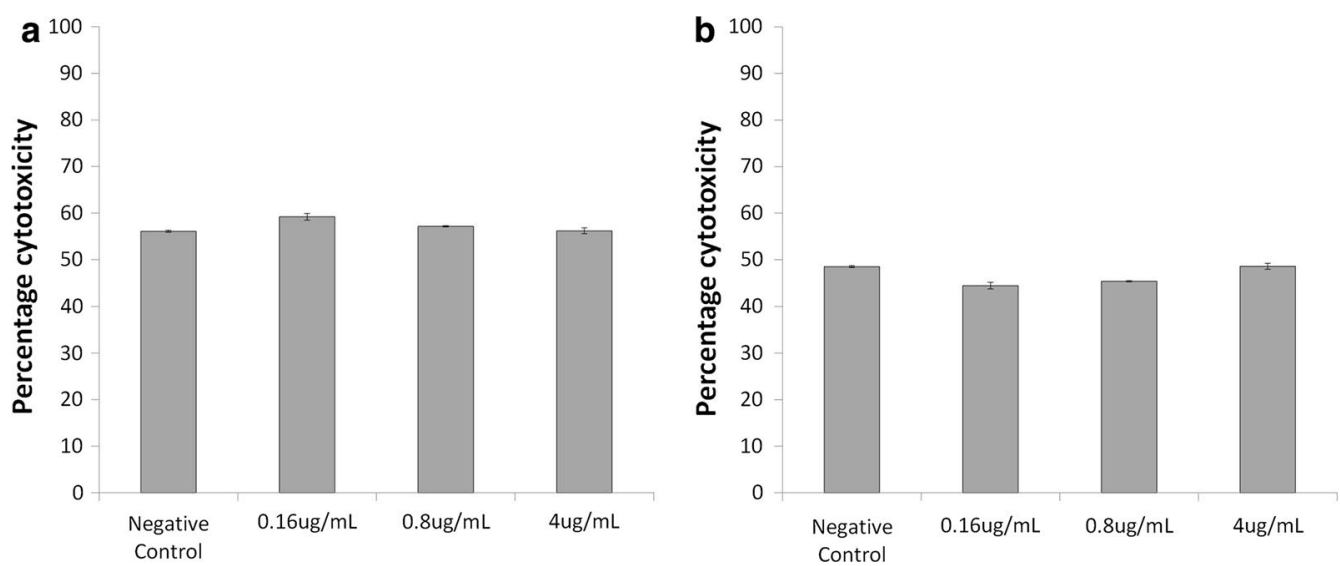

Fig. 7 Cytotoxicity of NK92 cells to HepG2 cells following treatment with efavirenz and efavirenz solid drug nanoparticles. NK92 cells were treated with either efavirenz aqueous solution (a) or efavirenz s $(\mathbf{b})$ for $24 \mathrm{~h}$ before their cytotoxic capability was assessed

\section{Discussion}

Understanding the interaction with immunological and haematological systems is vital to the preclinical evaluation of novel nanoparticle formulations for the treatment of disease. To date, only one study has investigated the impact of SDNs on immune function [51]. In order to determine whether SDNs composed of another drug behaved differently, a series of immune-activation criteria were conducted to assess whether the efavirenz nanoparticles trigger or interfere with immune responses. Throughout the experimental assessment, all incubations were conducted with equivalent drug concentrations of efavirenz between nanoparticle and aqueous solutions. Therefore, differences are due only to the nanoparticulate nature of the formulation.

Microbial contamination that may occur during the manufacturing process, particularly the introduction of endotoxin, can provide false positive results in several immunological assays. Prior to analysis of immune interactions, the amount of endotoxin present in both the efavirenz solution and the efavirenz SDNs was determined and found to be almost negligible. Hence, there was no evidence of microbial contamination following culture.

It is currently unclear if SDNs reach the blood, following oral administration, as intact nanoparticles but SDNs are being developed for several parenteral applications. Haemolysis can lead to various pathologies (e.g. anaemia and jaundice) and is a relatively common issue with environmental and medicinal nanoparticles [38, 52]. Therefore, to gain further confidence in SDN safety, we assessed haemolysis after incubation with whole blood from a healthy human volunteer. Aqueous efavirenz caused a significant amount of haemolysis. However, the efavirenz SDNs did not cause haemolysis, which is promising for SDNs being investigated for intravenous delivery. No impact on blood coagulation time in response to coagulation inducers was evident at the concentrations tested. Platelet aggregation was similarly unaffected by efavirenz SDNs and the test materials did not interfere with platelet activation induced by collagen. Complement activation has been reported for nanomaterials previously [50] so measurement of $\mathrm{iC} 3 \mathrm{~b}$ was conducted (the common factor for all three complement pathways) in healthy volunteer plasma. No activation of $\mathrm{iC} 3 \mathrm{~b}$ was observed following treatment suggesting that efavirenz SDNs do not activate complement via any of the main pathways.

No differences in phagocytic capacity were observed between MDM treated with SDNs or aqueous solution. Stimulation of MDM was also assessed using a panel of cytokines previously shown to be associated with macrophage activation. Neither the aqueous solution nor SDNs significantly stimulated cytokine secretion from MDM. Additionally, no difference in proliferation of PBMC from healthy volunteers was observed for SDNs or the aqueous solution, and neither interfered with proliferation in response to the known mitogen, PHA. The secretion of cytokines from PBMCs (IL-2, IL-10 and IFNY) was also similar for SDNs and aqueous solution, as was the impact on cytokine release in response to anti-CD3/anti-CD28 beads. IL-2, IL-10 and IFN $\gamma$ were chosen because of their secretion from $\mathrm{T}$ cells following $\mathrm{T}$ cell receptor activation [53-55]. Anti CD3/anti-CD28 beads bind and activate CD3 (T-cell receptor) and CD28 (co-stimulatory receptor) and are an established tool for inducing T-cell activation [56-58]. Finally, the expression of cell surface receptors associated with T-cell activation [59-62] was monitored in response to incubation with the efavirenz SDNs or an efavirenz aqueous solution. Again, no differences in expression in either CD4+ 
or CD8+ T cells between SDNs and an aqueous solution and no differences in the response to anti-CD3/antiCD28 beads were observed. NK92 cells were used as a model of primary NK cells to assess potential immunosuppression by efavirenz SDNs and no impact on NK92 cytotoxicity was observed. Therefore, in this ex vivo analysis, no immunological safety concerns were uncovered using the employed assays. Contrary to other reported nanoparticles, the SDNs presented here do not appear to interact with the immune system in the same way. Taken collectively with the previous observations with lopinavir SDNs, this particular nano-specific interaction does not appear to be a concern with SDN formulations, which bodes well for parenterally administered materials of this type. However, it should be noted that since SDNs are manufactured from the drug itself, one cannot rule out that their formation will not confer augmentation of molecule-specific interactions.

In summary, a previously pharmacologically optimised SDN formulation of efavirenz with improved bioavailability, in vitro cellular distribution and antiretroviral activity [43], did not interfere with components of the immune system in the studied assays, and exhibited favourable blood-contact properties. The emulsion-templated freeze drying platform may have broad application for optimising drugs with solubility/bioavailability issues. All excipients used are on the FDA CDER list and the resultant SDNs are physically similar to currently licensed SDN products.

\section{Conclusions}

The pharmacologically optimised efavirenz SDNs presented here have shown to be immunologically and haematologically inert in the in vitro/ex vivo preclinical assessment. The methodologies utilised can now be used to assess future nanomaterials as part of a preclinical assessment, to de-risk translation into clinical evaluation.

\section{Additional files}

Additional file 1: Table S1. Guide to settings and reagent requirements for assessment of plasma coagulation times of human plasma in response to treatment with nanoparticles.

Additional file 2: Figure S1. Physical-chemical characterisation of efavirenz solid drug nanoparticles. SDNs were dispersed in deionised water, PBS or $\mathrm{NaCl}(10 \mathrm{mM})$ at a concentration of $1 \mathrm{mg} / \mathrm{mL}$. Sample hydrodynamic size (a) and polydispersity index (b) were assessed using dynamic light scattering (DLS) analysis. Zeta potential (c) was also assessed at two different $\mathrm{pH}$.

Additional file 3: Figure S2. Detection of possible microbial contamination in sample materials via growth on LB agar plates. Sample materials were spread on LB agar plates and incubated for 48 hours in a humidified incubator. E. coli (a) was used as a positive control for microbial growth while LAL reagent water (b) was used as a negative control. Aqueous efavirenz was tested at $4 \mu \mathrm{g} / \mathrm{mL}$ (c) and $40 \mu \mathrm{g} / \mathrm{mL}$ (d) as well as efavirenz $\operatorname{SDN}(e, 4 \mu \mathrm{g} / \mathrm{mL}$ and f, $40 \mu \mathrm{g} / \mathrm{mL})$.

\section{Abbreviations}

APC: allophycocyanin; API: active pharmaceutical ingredient; aPTT: activated partial thromboplastin time; ATP: adenosine triphosphate; AUC: area under the curve; CD-: cluster of differentiation-; CMH: cyanomethaemoglobin; $\mathrm{CV}$ : coefficient of variation; DIC: disseminated intravascular coagulopathy; DMSO: dimethyl sulphoxide; DPBS: Dulbecco's phosphate buffered saline; EFV: efavirenz; ELISA: enzyme linked immunosorbant assay; EU: endotoxin units; FBS: foetal bovine serum; FITC: fluorescein isothiocyanate; HEPES: 4-(2-hydroxyethyl)piperazine-1-ethanesulfonic acid, N-(2-hydroxyethyl) piperazine- $N^{\prime}$-(2-ethanesulfonic acid); IEC: inhibition/enhancement controls; IFNY: interferon gamma; IL-: interleukin-; IMDM: Iscove's Modified Dulbecco's medium; LAL: limulus amoebocyte lysate; LB: Luria broth; LPS: lipopolysaccharide; M-CSF: macrophage colony stimulating factor; MDM: monocyte derived macrophages; NK: natural killer; PAMAM: polyaminoamine; PBMC: peripheral blood mononuclear cells; PCC: physical-chemical characteristics; PCR: polymerase chain reaction; PDFT: percent difference from theoretical; Pdi: polydispersity index; PE: phycoerythrin; PFC: perfluorocarbon; PFH: plasma free haemoglobin; PHA: phytohaemagglutinin; PLGA: poly(lactic-co-glycolic) acid; PPP: Platelet Poor Plasma; PRP: platelet rich plasma; PT: prothrombin time; PVA: poly(vinyl alcohol); rpm: revolutions per minute; RT-CES: real time cell electronic sensing; SDN: solid drug nanoparticle; SDN: standard deviation; TBH: total blood haemoglobin; Th1:T helper 1; Th2: Thelper 2; TNFa: tumour necrosis factor a; TPGS: D-a-tocopherol polyethylene glycol succinate; TT: thrombin time.

\section{Authors' contributions}

NJL conceived, carried out and analysed the experimental work, in addition to writing the manuscript. MG formulated the solid drug nanoparticles, performed physicochemical characterisation and reviewed the manuscript. All authors read and approved the final manuscript.

\section{Author details}

${ }^{1}$ Department of Molecular and Clinical Pharmacology, Institute of Translational Medicine, The University of Liverpool, 70 Pembroke Place, Block H, First Floor, Liverpool L69 3GF, UK. ${ }^{2}$ Department of Chemistry, The University of Liverpool, Liverpool, UK. ${ }^{3}$ European Nanomedicine Characterisation Laboratory, Department of Molecular and Clinical Pharmacology, Institute of Translational Medicine, The University of Liverpool, Liverpool, UK.

\section{Acknowledgements}

The authors acknowledge Dr. Marina Dobrovolskaia and Dr. Jeffrey Clogston for helpful discussions as well as Timothy Potter, Barry Neun and Jamie Rodriguez for excellent technical assistance. Sterility data, haemato-compatibility and NK cell RT-CES data were generated by the author (NJL) using the US Nanotechnology Characterization Laboratory operated by Leidos Biomedical Research Inc. for the National Cancer Institute.

\section{Competing interests}

The authors have no other relevant affiliations or financial involvement with any organization or entity with a financial interest in or financial conflict with the subject matter or materials discussed in the manuscript apart from those disclosed. SR, AO, MG and TM are inventors on a patent filing describing the use of atovaquone SDNs. No writing assistance was utilized in the production of this manuscript.

\section{Availability of data and materials}

The datasets used and/or analysed during the current study are available from the corresponding author on reasonable request.

\section{Consent for publication}

Not applicable.

\section{Ethics approval and consent to participate}

Ethics approval was granted from the University Physical Interventions sub-committee (Reference RETH000563). Informed consent was given and accepted by the healthy volunteers for use of whole blood in subsequent assays.

\section{Funding}

This work was funded by the UK Engineering and Physical Sciences Research Council (EPSRC—EP/G066272/1; EP/K002201/1). 


\section{Publisher's Note}

Springer Nature remains neutral with regard to jurisdictional claims in published maps and institutional affiliations.

Received: 8 November 2017 Accepted: 9 March 2018

Published online: 15 March 2018

\section{References}

1. Johnston H, Brown D, Kermanizadeh A, Gubbins E, Stone V. Investigating the relationship between nanomaterial hazard and physicochemical properties: informing the exploitation of nanomaterials within therapeutic and diagnostic applications. J Control Release. 2012;164:307-13.

2. Ferin J, Oberdorster G, Penney DP. Pulmonary retention of ultrafine and fine particles in rats. Am J Respir Cell Mol Biol. 1992;6:535-42.

3. Li XY, Brown D, Smith S, MacNee W, Donaldson K. Short-term inflammatory responses following intratracheal instillation of fine and ultrafine carbon black in rats. Inhal Toxicol. 1999:11:709-31.

4. Brown DM, Wilson MR, MacNee W, Stone V, Donaldson K. Size-dependent proinflammatory effects of ultrafine polystyrene particles: a role for surface area and oxidative stress in the enhanced activity of ultrafines. Toxicol Appl Pharmacol. 2001;175:191-9.

5. Gaiser BK, Fernandes TF, Jepson M, Lead JR, Tyler CR, Stone V. Assessing exposure, uptake and toxicity of silver and cerium dioxide nanoparticles from contaminated environments. Environ Health. 2009;8(Suppl 1):S2.

6. Dobrovolskaia MA, Aggarwal P, Hall JB, McNeil SE. Preclinical studies to understand nanoparticle interaction with the immune system and its potential effects on nanoparticle biodistribution. Mol Pharm. 2008:5:487-95.

7. Dobrovolskaia MA, McNeil SE. Immunological properties of engineered nanomaterials. Nat Nanotechnol. 2007;2:469-78.

8. Goppert TM, Muller RH. Polysorbate-stabilized solid lipid nanoparticles as colloidal carriers for intravenous targeting of drugs to the brain: comparison of plasma protein adsorption patterns. J Drug Target. 2005;13:179-87.

9. Leu D, Manthey B, Kreuter J, Speiser P, DeLuca PP. Distribution and elimination of coated polymethyl [2-14C]methacrylate nanoparticles after intravenous injection in rats. J Pharm Sci. 1984;73:1433-7.

10. Gref R, Minamitake Y, Peracchia MT, Trubetskoy V, Torchilin V, Langer R. Biodegradable long-circulating polymeric nanospheres. Science. 1994:263:1600-3.

11. Deng ZJ, Liang M, Monteiro M, Toth I, Minchin RF. Nanoparticle-induced unfolding of fibrinogen promotes Mac-1 receptor activation and inflammation. Nat Nanotechnol. 2011;6:39-44.

12. Westmeier $\mathrm{D}$, Stauber $\mathrm{RH}$, Docter $\mathrm{D}$. The concept of bio-corona in modulating the toxicity of engineered nanomaterials (ENM). Toxicol Appl Pharmacol. 2016;299:53-7.

13. Radauer-Preiml I, Andosch A, HawranekT, Luetz-Meindl U, Wiederstein M, Horejs-Hoeck J, Himly M, Boyles M, Duschl A. Nanoparticle-allergen interactions mediate human allergic responses: protein corona characterization and cellular responses. Part Fibre Toxicol. 2016;13:3.

14. Francian A, Mann K, Kullberg M. Complement C3-dependent uptake of targeted liposomes into human macrophages, B cells, dendritic cells, neutrophils, and MDSCs. Int J Nanomed. 2017;12:5149-61.

15. Kivisakk P, Alm GV, Fredrikson S, Link H. Neutralizing and binding anti-interferon-beta (IFN-beta) antibodies. A comparison between IFN-beta-1a and IFN-beta-1b treatment in multiple sclerosis. Eur J Neurol. 2000;7:27-34

16. Swanson SJ, Ferbas J, Mayeux P, Casadevall N. Evaluation of methods to detect and characterize antibodies against recombinant human erythropoietin. Nephron Clin Pract. 2004;96:c88-95.

17. Chen BX, Wilson SR, Das M, Coughlin DJ, Erlanger BF. Antigenicity of fullerenes: antibodies specific for fullerenes and their characteristics. Proc Natl Acad Sci USA. 1998;95:10809-13.

18. Braden BC, Goldbaum FA, Chen BX, Kirschner AN, Wilson SR, Erlanger BF. X-ray crystal structure of an anti-Buckminsterfullerene antibody fab fragment: biomolecular recognition of C(60). Proc Natl Acad Sci USA. 2000;97:12193-7.
19. Andreev SM, Babakhin AA, Petrukhina AO, Romanova VS, Parnes ZN Petrov RV. Immunogenic and allergenic properties of fulleren conjugates with aminoacids and proteins. Dokl Biochem. 2000;370:4-7.

20. Aggarwal P, Hall JB, McLeland CB, Dobrovolskaia MA, McNeil SE. Nanoparticle interaction with plasma proteins as it relates to particle biodistribution, biocompatibility and therapeutic efficacy. Adv Drug Deliv Rev. 2009:61:428-37.

21. Tan Y, Li S, Pitt BR, Huang L. The inhibitory role of CpG immunostimulatory motifs in cationic lipid vector-mediated transgene expression in vivo. Hum Gene Ther. 1999;10:2153-61.

22. van Zijverden M, Granum B. Adjuvant activity of particulate pollutants in different mouse models. Toxicology. 2000;152:69-77.

23. Diwan M, Elamanchili P, Cao M, Samuel J. Dose sparing of CpG oligodeoxynucleotide vaccine adjuvants by nanoparticle delivery. Curr Drug Deliv. 2004;1:405-12.

24. Lutsiak ME, Kwon GS, Samuel J. Biodegradable nanoparticle delivery of a Th2-biased peptide for induction of Th1 immune responses. J Pharm Pharmacol. 2006:58:739-47.

25. Chong CS, Cao M, Wong WW, Fischer KP, Addison WR, Kwon GS, Tyrrell $\mathrm{DL}$, Samuel J. Enhancement of Thelper type 1 immune responses against hepatitis B virus core antigen by PLGA nanoparticle vaccine delivery. J Control Release. 2005:102:85-99.

26. Cui Z, Mumper RJ. Coating of cationized protein on engineered nanoparticles results in enhanced immune responses. Int J Pharm. 2002;238:229-39.

27. Cui Z, Patel J, Tuzova M, Ray P, Phillips R, Woodward JG, Nath A, Mumper RJ. Strong T cell type-1 immune responses to HIV-1 Tat (1-72) proteincoated nanoparticles. Vaccine. 2004;22:2631-40.

28. Balenga NA, Zahedifard F, Weiss R, Sarbolouki MN, Thalhamer J, Rafati S. Protective efficiency of dendrosomes as novel nano-sized adjuvants for DNA vaccination against birch pollen allergy. J Biotechnol. 2006;124:602-14.

29. Rajananthanan P, Attard GS, Sheikh NA, Morrow WJ. Novel aggregate structure adjuvants modulate lymphocyte proliferation and Th1 and Th2 cytokine profiles in ovalbumin immunized mice. Vaccine. 1999;18:140-52.

30. Shaunak S, Thomas S, Gianasi E, Godwin A, Jones E, Teo I, Mireskandari K, Luthert P, Duncan R, Patterson S, et al. Polyvalent dendrimer glucosamine conjugates prevent scar tissue formation. Nat Biotechnol. 2004;22:977-84.

31. Cromer JR, Wood SJ, Miller KA, Nguyen T, David SA. Functionalized dendrimers as endotoxin sponges. Bioorg Med Chem Lett. 2005;15:1295-8.

32. Waters KM, Masiello LM, Zangar RC, Tarasevich BJ, Karin NJ, Quesenberry RD, Bandyopadhyay S, Teeguarden JG, Pounds JG, Thrall BD. Macrophage responses to silica nanoparticles are highly conserved across particle sizes. Toxicol Sci. 2009;107:553-69.

33. Hamerman JA, Ogasawara K, Lanier LL. NK cells in innate immunity. Curr Opin Immunol. 2005;17:29-35.

34. Sun JC, Lanier LL. Natural killer cells remember: an evolutionary bridge between innate and adaptive immunity? Eur J Immunol. 2009;39:2059-64.

35. Shin JH, Zhang L, Murillo-Sauca O, Kim J, Kohrt HE, Bui JD, Sunwoo JB. Modulation of natural killer cell antitumor activity by the aryl hydrocarbon receptor. Proc Natl Acad Sci USA. 2013;110:12391-6.

36. Biron CA. Yet another role for natural killer cells: cytotoxicity in immune regulation and viral persistence. Proc Natl Acad Sci USA. 2012;109:1814-5.

37. Mitchell LA, Gao J, Wal RV, Gigliotti A, Burchiel SW, McDonald JD. Pulmonary and systemic immune response to inhaled multiwalled carbon nanotubes. Toxicol Sci. 2007;100:203-14.

38. Ilinskaya AN, Dobrovolskaia MA. Nanoparticles and the blood coagulation system. Part II: safety concerns. Nanomedicine (Lond). 2013;8:969-81.

39. Greish K, Thiagarajan G, Herd H, Price R, Bauer H, Hubbard D, Burckle A, Sadekar S, Yu T, Anwar A, et al. Size and surface charge significantly influence the toxicity of silica and dendritic nanoparticles. Nanotoxicology. 2012:6:713-23.

40. McGuinnes C, Duffin R, Brown S, Mills N, Megson IL, Macnee W, Johnston S, Lu SL, Tran L, Li R, et al. Surface derivatization state of polystyrene latex nanoparticles determines both their potency and their mechanism of causing human platelet aggregation in vitro. Toxicol Sci. 2011;119:359-68.

41. Vercellotti GM, Hammerschmidt DE, Craddock PR, Jacob HS. Activation of plasma complement by perfluorocarbon artificial blood: probable 
mechanism of adverse pulmonary reactions in treated patients and rationale for corticosteroids prophylaxis. Blood. 1982;59:1299-304.

42. Choi J, Reipa V, Hitchins VM, Goering PL, Malinauskas RA. Physicochemical characterization and in vitro hemolysis evaluation of silver nanoparticles. Toxicol Sci. 2011;123:133-43.

43. McDonald TO, Giardiello M, Martin P, Siccardi M, Liptrott NJ, Smith D, Roberts P, Curley P, Schipani A, Khoo SH, et al. Antiretroviral solid drug nanoparticles with enhanced oral bioavailability: production, characterization, and in vitro-in vivo correlation. Adv Healthc Mater. 2014;3:400-11.

44. Liptrott NJ, Giardiello M, McDonald TO, Rannard SP, Owen A. Lack of interaction of lopinavir solid drug nanoparticles with cells of the immune system. Nanomedicine (Lond). 2017;12:2043-54.

45. Venor $^{\mathrm{TM}}$ GeM Mycoplasma Detection Kit [PCR-based].

46. Krzyzaniak JF, Alvarez Nunez FA, Raymond DM, Yalkowsky SH. Lysis of human red blood cells. 4. Comparison of in vitro and in vivo hemolysis data. J Pharm Sci. 1997;86:1215-7.

47. Krzyzaniak JF, Raymond DM, Yalkowsky SH. Lysis of human red blood cells 1: effect of contact time on water induced hemolysis. PDA J Pharm Sci Technol. 1996;50:223-6.

48. Krzyzaniak JF, Yalkowsky SH. Lysis of human red blood cells. 3: effect of contact time on surfactant-induced hemolysis. PDA J Pharm Sci Technol. 1998:52:66-9.

49. Amin K, Dannenfelser RM. In vitro hemolysis: guidance for the pharmaceutical scientist. J Pharm Sci. 2006;95:1173-6.

50. Szebeni J, Alving CR, Savay S, Barenholz Y, Priev A, Danino D, Talmon Y. Formation of complement-activating particles in aqueous solutions of Taxol: possible role in hypersensitivity reactions. Int Immunopharmacol. 2001;1:721-35.

51. Liptrott NJ, Giardiello M, McDonald TO, Rannard SP, Owen A. Lack of interaction of lopinavir solid drug nanoparticles with cells of the immune system. Nanotoxicology. 2017;12:2043-54 (Submitted)

52. Dobrovolskaia MA, Clogston JD, Neun BW, Hall JB, Patri AK, McNeil SE. Method for analysis of nanoparticle hemolytic properties in vitro. Nano Lett. 2008:8:2180-7.

53. Bento CA, Hygino J, Andrade RM, Saramago CS, Silva RG, Silva AA, Linhares UC, Brindeiro R, Tanuri A, Rosenzwajg M, et al. IL-10-secreting T cells from HIV-infected pregnant women downregulate HIV-1 replication: effect enhanced by antiretroviral treatment. AIDS. 2009;23:9-18.

54. Nelson BH. IL-2, regulatory T cells, and tolerance. J Immunol. 2004;172:3983-8.

55. Stybayeva G, Kairova M, Ramanculov E, Simonian AL, Revzin A. Detecting interferon-gamma release from human CD4 T-cells using surface plasmon resonance. Colloids Surf B Biointerfaces. 2010;80:251-5.

56. Diveu C, McGeachy MJ, Boniface K, Stumhofer JS, Sathe M, Joyce-Shaikh B, Chen Y, Tato CM, McClanahan TK, de Waal Malefyt R, et al. IL-27 blocks RORc expression to inhibit lineage commitment of Th17 cells. J Immunol. 2009:182:5748-56.

57. Duraisingham SS, Hornig J, Gotch F, Patterson S. TLR-stimulated CD34 stem cell-derived human skin-like and monocyte-derived dendritic cells fail to induce Th17 polarization of naive T cells but do stimulate Th1 and Th17 memory responses. J Immunol. 2009;183:2242-51.

58. Sattler A, Wagner U, Rossol M, Sieper J, Wu P, Krause A, Schmidt WA, Radmer S, Kohler S, Romagnani C, Thiel A. Cytokine-induced human IFN-gamma-secreting effector-memory Th cells in chronic autoimmune inflammation. Blood. 2009;113:1948-56.

59. dos Santos DC, Neves PC, Azeredo EL, Pelajo-Machado M, Martinho JM, Pacheco-Moreira LF, Araujo CC, Cruz OG, de Oliveira JM, Pinto MA. Activated lymphocytes and high liver expression of IFN-gamma are associated with fulminant hepatic failure in patients. Liver Int. 2012;32:147-57.

60. Hosono M, de Boer OJ, van der Wal AC, van der Loos CM, Teeling P, Piek $\mathrm{JJ}$, Ueda M, Becker AE. Increased expression of T cell activation markers (CD25, CD26, CD40L and CD69) in atherectomy specimens of patients with unstable angina and acute myocardial infarction. Atherosclerosis. 2003;168:73-80.

61. Mitchell DM, Williams MA. An activation marker finds a function. Immunity. 2010;32:9-11.

62. Pawlowska J, Smolenska Z, Daca A, Witkowski JM, Bryl E. Older age of rheumatoid arthritis onset is associated with higher activation status of peripheral blood CD4(+) T cells and disease activity. Clin Exp Immunol. 2011;163:157-64

\section{Submit your next manuscript to BioMed Central and we will help you at every step:}

- We accept pre-submission inquiries

- Our selector tool helps you to find the most relevant journal

- We provide round the clock customer support

- Convenient online submission

- Thorough peer review

- Inclusion in PubMed and all major indexing services

- Maximum visibility for your research

Submit your manuscript at www.biomedcentral.com/submit
() Biomed Central 